\title{
The Role of Verbal Threat Information in the Development of Childhood Fear. "Beware the Jabberwock!"
}

\author{
Peter Muris $\cdot$ Andy P. Field
}

Published online: 3 March 2010

(c) The Author(s) 2010. This article is published with open access at Springerlink.com

\begin{abstract}
Rachman's (Behaviour Research and Therapy 15:372-387, 1977; Clinical Psychology Review 11:155$173,1991)$ three pathways theory proposed that childhood fears not only arise as a consequence of direct learning experiences, but can also be elicited by means of threat information transmission. This review looks at the scientific evidence for this idea, which has accumulated during the past three decades. We review research on the influences of media exposure on children's fears, retrospective parent and child reports on the role of threat information in fear acquisition, and experimental studies that explored the causal effects of threat information on childhood fears. We also discuss possible mechanisms by which threat information exerts its influence and the processes relevant to understand the role of this type of learning experience in the origins of fear. Finally, implications for the prevention and intervention of childhood fears are briefly explored, and potential leads for future research will be highlighted.
\end{abstract}

Keywords Threat information $\cdot$ Fear $\cdot$ Children

P. Muris $(\bowtie)$

Institute of Psychology, Erasmus University Rotterdam,

Burgemeester Oudlaan 50, Suite T13-37, Postbus 1738, 3000 DR

Rotterdam, The Netherlands

e-mail: muris@fsw.eur.nl

A. P. Field

University of Sussex, Brighton, United Kingdom

\section{Introduction}

"Beware the Jabberwock, my son!

The jaws that bite, the claws that catch!

Beware the Jubjub bird, and shun

the frumious Bandersnatch!"

(Carroll, 1872/1998; p. 132)

This citation from Lewis Carroll's "Through the lookingglass" is part of the poem "Jabberwocky," read by Alice (of "Alice's adventures in wonderland" fame). Although Alice did not seem to become fearful and anxious upon reading this poem, the story contains pieces of information that refer to the potential dangerousness of the Jabberwock, Jubjub bird, and Bandersnatch (e.g., beware, bite, claws). Threat information has, for centuries, formed an intrinsic part of culture, folklore and society (Ragan 2006): around $41 \%$ of a sample of nursery rhymes was violent in some way (Davies et al. 2004). Whether it was gathered around fires, or huddled in houses, or even sat at the bedside, people have recounted folktales that have been both allegories of real danger or ways to turn fear into hope or action (Ragan 2006; Zipes 1979). Developmental psychologists have occasionally criticized fairy tales for being brutal, cruel, frightening, and unrealistic portrayals of the world (Sale 1978). However, arguably these tales have served an adaptive function in preparing children for fear and, more important, teaching them to cope with fear. Threat information permeates not just folk tales, but the everyday dialog of families, and in more recent times the media (see Comer and Kendall 2007 for a review). As such, threat information has become to be seen as an important part of the etiology of fear (Rachman 1977, 1991).

The present article provides an overview of the studies that have investigated the role of threat information in the acquisition of childhood fear and anxiety. First, we will 
provide a brief overview of research on childhood fears and phobias, with a specific focus on the origins of these phenomena. Then, we describe the theoretical background that formed the basis for the research on threat information and its role in the acquisition of fears and phobias. Next, evidence is summarized of studies that examined the role of threat information learning by means of retrospective accounts in children and adolescents that already display fear, phobia, or some other anxiety problem. Following this, an experimental paradigm will be described that enables us to investigate the causal influence of threat information on the acquisition of fears. We will summarize the findings of research that has employed this paradigm to explore its effects on children's fear beliefs and related phenomena such as avoidance behavior and anxiety-related cognitive biases. In the next section, we will discuss the mechanisms by which threat information exerts its influence and the processes relevant to understand how this type of learning experience contributes to the acquisition of childhood fears. The review closes with a summary on the role of threat information in the etiology of childhood fears and phobias, a discussion of its possible (clinical) implications and potential leads for future research.

\section{Theoretical Background}

Any model that attempts to explain the transmission of fear has to potentially explain all characteristics of the fear emotion. The fear emotion has been described in different ways and explained through many different theoretical models. According to Lang (1968, 1985), an emotion consists of three response systems: (1) subjective states and cognitions associated with those states (i.e., verbal-cognitive responses); (2) behavioral changes; and (3) physiological states. This tripartite model is well accepted as a theoretical account (see also Merckelbach et al. 1996a), but is also the scaffolding for a recent formulation of treatment for child anxiety (Davis and Ollendick 2005). As such, models of how fears develop during childhood have to explain how each of these components might be changed during the course of development.

\section{Childhood Fears and Phobias}

Research has indicated that fear is a highly prevalent phenomenon during the development of children (Gullone 2000). Survey- and interview-based studies have shown that it is common for young people across various ages to report fears in relation to animals (e.g., spiders, dogs), medical affairs (e.g., injection, dentist), and situational and environmental challenges (e.g., heights, the dark). A review of these studies estimated that the average child has between two and five of such fears, but there is considerable variation across studies with one study (Ollendick et al. 1989) reporting an average of 14 fears per child (see Gullone 2000). Although such fears are in essence considered as benign, there is also evidence indicating that they reflect more serious anxiety problems in a sizable minority of the children. For example, Muris et al. (2000b) explored the severity of children's main fear by means of a structured diagnostic interview for measuring phobias and anxiety disorders in terms of the criteria of the Diagnostic and Statistical Manual of Mental Disorders, fourth edition (DSM-IV; American Psychiatric Association 1994). Results demonstrated that childhood fears reflected significant phobias and anxiety disorders in about one-fifth (i.e., 22.8\%) of the children, which implies that in these cases fears interfered significantly with their daily routine (see also Muris and Merckelbach 2000).

Evidence from the literature on adult phobias also shows that fears during childhood should be taken seriously. Öst (1987), for instance, interviewed adult phobic patients about the age of onset of their anxiety problems, and noted that specific phobias tend to begin at a fairly young age: animal phobias had an onset age as early as 7 years, followed by blood phobia (9 years), dental phobia (12 years), and social phobia (16 years). Many authors have noted that these ages of onset map onto the developmental pattern of normal fears (e.g., Field and Davey 2001; Muris and Field in press): in early childhood years normative fears are concerned with being separated from their parents and animals, then selfinjury concerns become prominent in middle childhood (Bauer 1976), before moving to social-evaluative apprehension in preadolescence and adolescence (Westenberg et al. 2004). This developmental pattern of fear seems to mirror evolutionary concerns. Öhman et al. (1985) have argued that evolution has selected for fear and avoidance of potentially dangerous stimuli and situations. At a very young age, children are still defenseless and so innate fears will keep infants within protective distance of their parents. When children grow physically (4-8 years) they will explore their environment alone, but as they are still vulnerable it will be vital for them to learn about animal threats efficiently at this age. By the teenage years, natural wariness of predators should wane because the child is cognitively stronger. However, the social position within the group will become more important and evolution might select for a system that, at this age, shifts the focus of threat into the social world. Any causal explanation of children's fears needs to explain these apparent developmental patterns and fit within this evolutionary framework.

\section{Origins of Extreme Fears}

Although fears are mild and non-pathological in most youths, there is a subgroup of children who display such 
high fear levels that they qualify for the diagnosis of a phobia, which may even persist into adulthood (e.g., Kessler et al. 2005). This observation has inspired current developmental psychopathology theories, in which it is assumed that phobias should be conceived as extreme manifestations of normal developmental fears. For some reason, these fears have radicalized and acquired pathological properties (Craske 2003; Muris 2007). Factors that contribute to the origins of extreme fears in children generally fall in two broad categories, namely genetics and environmental influences. With regard to genetics, there is evidence from twin studies showing that heritability accounts for a significant proportion of the variance in childhood fear. For example, Stevenson et al. (1992) compared the frequency of self-reported fears in monozygotic and dizygotic twin pairs with ages ranging between 8 and 16 years. The researchers found that a twin's level of fearfulness could be predicted from the co-twin's score. Furthermore, the frequency of fear was more similar in monozygotic than in dizygotic twin pairs, which confirms that there was a significant influence of heritability on children's fear levels (see also Lichtenstein and Annas 2000; Rose and Ditto 1983).

Behavioral-genetic research has demonstrated that depending on the type of fear under study up to $50 \%$ of the variance in childhood fears can be explained by the genetic factor (Eley and Gregory 2004). Therefore, a substantial proportion of the variance in the development of high fear levels in children must be explained by environmental factors. When considering environmental influences on childhood fears, discrete learning experiences seem to be particularly important. Rachman $(1977,1991)$ theorized that there are three main routes along which fears and phobias can be learned. The first pathway is classical conditioning, which can be nicely illustrated by Watson and Rayner's (1920) Little Albert experiment. In this experiment, a white rat was presented to an 11-month-old boy, who initially displayed no obvious fear of the animal. However, whenever Albert approached the animal, the experimenters frightened (the unconditioned response, UR) Albert by producing a loud noise (the unconditioned stimulus, US) by striking a steel bar behind the boy's head. After five such experiences, Albert became very upset (the conditioned response, CR) by the sight of the white rat, even though the loud noise was no longer presented. The fear originally associated with the loud noise had come to be elicited by the previously neutral stimulus, the white rat (now the conditioned stimulus, CS). This basic model is the foundation of many contemporary theories of fear acquisition and there is a wealth of laboratory and real-world evidence to validate its causal status as a route to fear (see Davey 1997; Field 2006a; Mineka and Zinbarg 2006; Öhman and Mineka 2001).
The second route is concerned with modeling or vicarious learning and refers to the phenomenon that fear is acquired by observing another person's fearful reaction to a stimulus or situation. Over 40 years a plethora of experimental research in both adults and children has shown that vicarious learning is also a viable pathway to fear (see Askew and Field 2008 for an extensive review).

The third route is fear acquired through the transmission of verbal threat information, and boils down to the idea that children may become fearful when they hear or read that a stimulus or situation might be dangerous or have another negative connotation. Rachman (1977) has posited that this pathway is particularly relevant for understanding the origins of childhood fears and phobias: "Information-giving is an inherent part of child-rearing and is carried on by parents and peers in an almost unceasing fashion, particularly in the child's earliest years. It is probable that informational and instructional processes provide the basis for most of our commonly encountered fears of everyday life" (p. 384). Given its presumed importance, and the fact that comprehensive reviews have appeared recently on the role of the conditioning and vicarious learning pathways in the acquisition of childhood fears and phobias (Askew and Field 2008; Field 2006a), the current article focuses solely on the causal status of verbal threat information as a pathway to fear. The only previous review on the relevance of Rachman's $(1977,1991)$ three pathways theory for the etiology of childhood phobias (King et al. 1998) was published more than a decade ago, and important new insights have emerged in the past 10 years (see Fisak and Grills-Taquechel 2007) making this contemporary overview of the literature timely. The present review was based on an examination of the psychological literature by means of PsycInfo using "fear/anxiety" and "children/adolescents" in combination with "media" ("Effects of the Media on Children's Fears"), "Rachman/pathways/origins" ("Child and Parent Reports on the Origins of Fear"), and "verbal/negative/threat information" ("Experimental Research on the Effects of Threat Information on Childhood Fears") as search terms. Further, references of found articles were carefully checked in order to prevent that relevant studies would be missed.

\section{Evidence for Threat Information as a Pathway to Childhood Fear}

\section{Effects of the Media on Children's Fears}

The media represent a notable way through which children might be exposed to threat information. To begin with, there is evidence from retrospective research indicating that many adults remember an incident from their 
childhood during which they were really frightened by a $\mathrm{TV}$ program or movie, and that these fears bothered them for years. For example, Harrison and Cantor (1999) administered a questionnaire to their sample of undergraduate students asking them whether they had ever seen a television show or movie that frightened or disturbed them so much that the emotional effect endured after the TV show or movie was over. Ninety percent of the participants reported such an experience and recalled that this incident had occurred at some time during their youth. Interestingly, a substantial minority of the participants (i.e., 26.1\%) reported that they were still experiencing residual fear in relation to the event, and some of them even indicated that they still avoided the stimulus or situation depicted in the program or movie (see also Hoekstra et al. 1999).

There are also studies that actually examined the relationship between violent or otherwise threatening information presented on television and fright reactions in child samples. This has been done by simply asking parents whether they ever noticed that their child had become frightened by something that they had seen on television (e.g., Cantor and Nathanson 1996) or by interviewing the children themselves about fears and worries that had arose following TV programs and movies with a scary content (e.g., Valkenburg et al. 2000; Van der Molen and Bushman 2008). This type of research has indicated that about onethird of the youths appear to exhibit fear reactions in response to threat information displayed on television or in films (see for a review Cantor 1998).

Several investigators have explored whether the amount of media use has any impact on children's perception of threat. For example, Smith and Wilson (2002) assessed the relation between the frequency of TV news viewing and emotional responses to everyday news stories in younger (i.e., 5-9 years) and older (i.e., 10-13 years) primary school children. The results demonstrated that frequency of news viewing was positively associated with children's threat perception. More precisely, children who more frequently watched the TV news estimated higher levels of crime occurring in a distant American city. In a similar vein, Comer et al. (2008) explored the link between children's media use and their perception of societal threat and personal vulnerability. Children indicated how many hours per week they watched television and how many hours per week they were online on the Internet. In addition, they were asked to rate the likelihood of future threatening events (i.e., crime, terrorism, earthquakes, hurricanes/ floods) occurring in the United States (i.e., societal threat) or happening to themselves (i.e., personal threat). It was found that children's television use was associated with elevated perceptions of personal vulnerability to major threats. No relations were observed between the amount of Internet use and threat perceptions and between media use and perceptions of societal threat. Other studies have looked at the impact of specific news events such as the assassination of the Dutch filmmaker Theo van Gogh (Buijzen et al. 2007). Children aged between 8 and 12 reported how often they had watched the news coverage (never, sometimes, often, or very often) and these estimates significantly predicted their fear, worry, anger and sadness (after controlling for age and gender). These effects were moderated in the young (i.e., 8- to 10-year-old) children by parenting: fear and worry were reduced in children whose parents helped them to understand what was happening in the news, but were exacerbated in children whose parents restricted them from watching the news. In a similar study, Smith and Moyer-Gusé (2006) examined the reactions of children and adolescents (aged 5-17) to television coverage of the war on Iraq. They found that exposure to war news significantly predicted safety concerns (which was essentially a measure of fear cognitions) but not a measure that tapped behavioral components of anxiety. However, the perceived realism of the news (i.e., parent ratings of their child's perceptions of the reality and seriousness of the war on Iraq) did significantly predict both cognitive and behavioral measures of fear as did age (with older children reporting greater fear).

Several studies have made the step from self-reported fears to looking at the effects of the media on clinical measures of anxiety (typically posttraumatic stress disorder or PTSD symptoms). For instance, Terr et al. (1999) carried out a field study examining children's fears and posttraumatic stress symptoms following the Challenger space shuttle explosion in January 1986. Two samples of children were compared: East Coast children who had seen a lot of TV coverage on the event, and West Coast children who just heard about the explosion when the study was conducted. Results indicated that more than $60 \%$ of the young participants in this study feared at least one stimulus related to the Challenger within the first two months after the explosion. The East Coast children-who had followed the news about the event via television-were more symptomatic than children from the West Coast, suggesting that media exposure produces distant-emotional effects in youths. Comparable findings have been obtained in children after terrorist attacks. In an excellent review, Comer and Kendall (2007) identify thirteen studies that have looked at the impact of media reports of terrorist attacks (the 1995 Oklahoma City bombing and 9/11 attacks) on children's anxiety. We will not re-review these studies but use two particularly valuable investigations that illustrate the general points from this body of research. Hoven et al. (2005) investigated the prevalence of psychopathology among New York City school children in the 6 months following the World Trade Center attack. Over 8000 children were included in the study, some of which had 
directly witnessed the tragic event, while others were only indirectly exposed via the media. Diagnostic interviews screening for PTSD and other probable mental disorders (e.g., anxiety disorders and mood disorders) showed that children who had directly witnessed the terrorist attacks were most frequently affected by PTSD and other mental problems. Interestingly and most pertinent to the present article, a substantial proportion of the children who were only indirectly exposed via the media also developed such problems: that is, $18.2 \%$ of them displayed clinically significant signs of PTSD, another anxiety disorder, or major depressive disorder. Comparable findings have been obtained in other studies examining children's responses to the 9/11 terrorist attacks (Holmes et al. 2007; Lengua et al. 2005; Otto et al. 2007). Of these other studies, Otto et al. (2007) deserves special mention because they looked at several demographic (e.g., age, gender, SES), peri-traumatic (e.g., amount of media coverage watched, child's distress at the time of events, pre-event psychiatric history, family discussions about the events, identification with the victims), pre-event psychiatric (e.g., behavioral inhibition, child anxiety, child and parent depression, parental panic disorder), and pre-event family (e.g., parental criticism, overinvolvement, family conflict) characteristics as mediators of posttraumatic symptoms at 7-month follow-up. The main findings of this study were that contrary to what might be expected, child anxiety, depression, and family psychiatric history did not significantly predict the severity of PTSD symptoms resulting from viewing media coverage of the $9 / 11$ attacks. The main significant predictors were the amount of media coverage watched (but only in children 10 years old or younger), identification with the victims, distress at the time of the attacks, changing viewing habits (to either avoid or watch more as events unfolded), and family expressiveness. This study also seemed to indicate that threat information might have a greater impact on younger children.

Altogether, the studies discussed in this section provide evidence to suggest that children who are exposed to threat information provided by the media (and in particular television) are (more) likely to develop fears. However, because of the naturalistic designs employed in these studies, it is not entirely clear whether the effects are entirely attributable to threat information provided by the media as it is also possible that other mechanisms have been at work to promote children's fear reactions. Television media do not only contain verbal information but also images and reactions that might, in themselves, be threatening or convey threatening information. For example, film footage of the 9/11 attacks such as people jumping from burning buildings would themselves be distressing and constitute direct conditioning experiences. In support of this idea, Otto et al. (2007) found that distress at the time of the attacks predicted later PTSD symptoms. News reports of the attacks also included vicarious information (people's reactions to the attacks). As such, although these studies are a brilliant naturalistic way to look at how fear develops in children, they are limited in what they tell us about the specific causal impact of threat information.

\section{Child and Parent Reports on the Origins of Fear}

Another way to investigate whether threat information transmission is involved in the etiology of childhood fears and phobias is to ask children and parents about their own ideas on the origins of the anxiety problems. Typically this type of research has relied on inventories or interviews that are based on the Phobic Origins Questionnaire (Öst and Hugdahl 1981), which measures the relative roles of Rachman's $(1977,1991)$ three pathways by asking questions about conditioning, modeling, and threat information experiences with the feared stimulus or situation. In this section, we will provide an overview of studies that relied on this method, of course with a special focus on the results obtained for the threat information pathway.

Parent report data seem to suggest that the contribution of threat information to childhood fear is rather modest. For example, Menzies and Clarke (1993) administered an origins questionnaire to the parents of 50 children with water phobia who applied for treatment at a university clinic. Parents had to indicate the level of influence in the onset of their child's fear from a list of alternatives covering Rachman's pathways. Fourteen percent of the parents reported that they had warned their child about the dangerousness of water-related activities or that their child had heard distressing stories about water. However, none of the parents pointed out that such threat information experiences were most influential in the acquisition of their child's fear. A similar result was obtained by Graham and Gaffan (1997) who examined the pathways to fear for a small sample of water phobic children $(N=9)$. Results showed that although many mothers (78\%) reported that their child had threat information experiences with water, none of them indicated that such events had played a role in the onset of the phobia. Other studies evaluating Rachman's theory from the parents' perspective indicated that the threat information pathway neither seems to make an important contribution to the acquisition of children's dog phobia (King et al. 1997) and dental fear (Milgrom et al. 1995). However, King et al. (1997, p. 77) rightly remarked that parental perceptions of fear acquisition "may be invalid in terms of what actually occurred," suggesting that it may also be important to ask children themselves to report on the possible pathways to their fears.

Several studies have investigated Rachman's pathways by questioning children about their learning experiences in 
relation to their main fear or phobia. In a large study including 1092 school children, Ollendick and King (1991) examined whether various learning experiences can be identified for the 10 most intense childhood fears as assessed by means of the Fear Survey Schedule for Children-Revised (FSSC-R; Ollendick 1983). More precisely, children who reported "a lot of fear" to FSSC-R items such as "Being hit by a car or truck," "Snakes," and so forth, were given a short questionnaire that asked them whether they had experienced conditioning, modeling, and/or threat information events in relation to these stimuli and situations. It was found that the vast majority of the children (89\%) reported a threat information experience (e.g., hearing or seeing frightening things about the stimulus or situation from parents, teachers, friends, television, movies, or newspapers) for these top intense fears, while conditioning and modeling were less often mentioned. Followup research (Doogan and Thomas 1992; Muris et al. 2008a; Muris et al. 1997; Muris et al. 2000a; Muris et al. 2001) has yielded highly comparable findings, indicating that threat information transmission is frequently reported by children as the dominant pathway to their main fear. Interestingly, in two of these studies (Muris et al. 1997; Muris et al. 2008a), children were also explicitly asked to what extent threat information (and other learning) experiences had actually played a role in the exacerbation ("Did the event cause you to become more fearful?") or onset ("Did your fear begin with this event?") of the fear. When employing these more stringent criteria, the percentages of children linking the origins of their fears to the threat information pathway were clearly smaller, although a considerable proportion (i.e., between one-fourth to one-third) of the children still reported that their fear had intensified or begun after hearing frightening things about the stimulus or situation.

Meanwhile, there are also empirical data suggesting that the threat information pathway is less relevant for understanding the origins of certain types of childhood fear. For example, in a study by Merckelbach et al. (1996b), children with a severe spider phobia were interviewed about their learning experiences with this animal, including threat information transmission. To cross-validate the responses provided by the children, parents were interviewed independently about the origins of their child's phobia. Only a small proportion of the children (i.e., 5\%) ascribed the onset of the phobia to a threat information event (see also Merckelbach and Muris 1997), and this percentage was even lower in the parents (i.e., 0\%). Remarkably, child and parent report data indicated that in about half of the children fear of spiders had always been present, thereby seriously questioning the importance of learning experiences such as threat information transmission in the etiology of this type of fear. Such observations have led some authors to propose that certain types of childhood fears (e.g., fear of spiders, heights, water, strangers, separation, and so on) are innate, spontaneous reactions to evolutionary pre-potent cues that occur without critical learning experiences involving these feared objects (Menzies and Clarke 1995; Poulton and Menzies 2002). However, this proposal is extremely difficult to substantiate and it may well be that these so-called inborn fears merely reflect general ideas about the pertinent stimuli that are so deeply rooted in mankind that they are transmitted from caregivers to their children from birth onward so that explicit learning events, such as threat information transmission, can no longer be recalled (e.g., Muris et al. 2002).

In spite of the fact that threat information is less frequently reported by children and their parents for some fears, there is abundant evidence from this type of research suggesting that this pathway plays a role in the origins of childhood fears. Nevertheless, studies employing inventories or interviews that are based on the Phobic Origins Questionnaire can be criticized because this retrospective method has various limitations (King et al. 1998): (1) the lack of control groups; (2) potential memory bias; and (3) the validity of the measurement instruments. The lack of control groups with either non-fearful or low fearful individuals in the majority of self-report studies makes it impossible to know whether particular types of learning events were more prevalent among individuals with fears than among those without. For example, in studies of high and low fearful participants, fear learning experiences are reported by similar numbers of high and low fearful people (Di Nardo et al. 1988; Ehlers et al. 1994; Hofmann et al. 1995; Merckelbach et al. 1992). Recall bias is a particular problem for studies that have asked adults to reflect upon the origin of their fears. For example, in one study over two-thirds of the sample could not remember the onset of their phobia (McNally and Steketee 1985). However, recall bias is less of a problem in studies that have asked children about the origins of their fears because of the relative recency of events. However, there are still likely biases arising from the saliency of events; for instance, direct traumatic events are likely to be more strongly encoded and, therefore, more easily retrieved than pieces of verbal information (Field et al. 2001). Finally, the measures that have been used to assess an individual's beliefs about the cause of their fear, but this may not be the actual cause. Some studies have tried to address this issue by crossvalidating children's data with data from parents (e.g., the aforementioned study by Merckelbach et al. 1996b) with the result that verbal information did not emerge as an important pathway to fear. Although these findings imply that verbal information is simply not a viable pathway to fear in children, it is possible that parents and children simply do not remember the relatively mild verbal 
information experiences that have contributed to fear. A particularly important criticism that relates to both memory bias and measure validity is that all of these retrospective reports measure attributions not actual causal events that contributed to fear. A child may well attribute their fear of dogs to a large dog barking at him in the park, but perhaps this event had an effect only against the background of his parents consistently telling him to be wary of dogs. People's attributions will be influenced by their own beliefs about how fears develop as well as the culture and society within which they live. As such, they will place subjective (rather than objective) weight upon certain experiences, which could lead to erroneous attributions about the cause of their fear. The likelihood is that fear emerges through an interaction between all of Rachman's pathways and temperamental and genetic vulnerabilities (e.g., Muris 2007). People are ill-placed to pick apart these complex interactions. As such, it is one thing to believe that your fear can (or cannot) be explained by verbal threat information but quite another to show it actually has a causal role in the development of fear. As such, although self-report research has been valuable both as a test of concept and in discovering to what people attribute their fears (which can be very useful clinically), it has been limited in what it can tell us both about the causal status of verbal threat information and its interactions with other variables in the development of fear.

\section{Experimental Research on the Effects of Threat} Information on Childhood Fears

In an attempt to deal with the critiques on naturalistic studies examining detrimental effects of media exposure and research investigating threat information transmission via retrospective child and parent report, Field et al. (2001) developed an experimental paradigm to explore the causal role of this pathway in the acquisition of childhood fears. ${ }^{1}$ With this method, it became possible to study the effects of threat information under more controlled conditions, thereby providing an excellent opportunity to learn more about the basic mechanisms underlying this learning pathway. There are several specific advantages to this experimental approach. First, you can get a purer picture of the effect of verbal information by eliminating other pathways. As we have seen, naturalistic studies that, e.g., look at media exposure focus on the effects of events that are likely to contain verbal information, directly traumatic images, and vicarious learning. Experimental manipulation

\footnotetext{
1 There are also older studies investigating the effects of threat information on children (e.g., Orbach et al. 1993), but this research focused on the general emotional impact of frightening stories in young people rather than the role of such information in the acquisition of fear for a specific stimulus or situation.
}

of verbal information alone enables firm conclusions to be drawn about the specific effect that it has on fear. Second, the parameters of verbal information as a pathway to fear can be explored. For example, does the source of information matter? Does verbal threat information have a greater effect in temperamentally vulnerable individuals? What type of information has the greatest impact? Can the impact of verbal information be mediated? Without a paradigm that specifically manipulates verbal information, these parameters cannot be explored. Third, by manipulating different pathways to fear in a systematic way, it is possible to look at how they might interact to produce fear responses. Finally, experimental manipulation of threat information opens up the possibility of exploring the underlying mechanism through which the pathway operates (which has potential benefits for prevention and reversing the effects that verbal information has). Given the benefits that an experimental approach affords, the current section will provide a comprehensive overview of the research findings that have been obtained with this paradigm.

\section{Description of the Basic Paradigm and First Results}

The general outline of this paradigm is simple and straightforward: children are confronted with various types of information about an unknown stimulus and before and after this experimental manipulation their level of fear for this object is assessed. "Fear" in these experiments can be measured from the perspective of any of Lang's (1968) aforementioned response systems: fear cognitions, avoidance behavior, or physiological responses. Fear cognitions are typically measured using self-report questions that require children to respond on a Likert scale to scenarios that cover different situations involving the stimulus. For example, Field et al. (2001) has employed the Fear Beliefs Questionnaire that consists of statements such as "Do you think that an X will bite you?" in which $\mathrm{X}$ is the name of an animal. To assess avoidance behavior, approach tasks have been used. For instance, Field and Lawson (2003) developed a task in which children were asked to put their hand into a box that they believed to contain a novel animal (the Touch Box Task). The box is either a wooden box or a cardboard pet-carrier box that have a circular hole cut at one end. This hole is covered by a Hessian curtain so that children cannot see into the box. The experimenter measures the time taken for the child to place their hand up to the wrist through the curtain and into the box. This socalled latency time is taken as an index of behavioral avoidance. Another measure of avoidance is the Nature Reserve Task developed by Field and Storksen-Coulson (2007), which consists of a wooden board covered in green material (to give the impression of grass). The edges have fences, bushes and trees made from brown (for wood) and 
green (for leaves) pipe cleaners. Photographs of two novel animals are placed at each end of the board. Children are told that the board represents a nature reserve, in which one type of animal lives at one end and another type at the other. They are asked to imagine they visit this nature reserve and are given a Lego figure (a boy for boys and a girl for girls) that represents them. Children place the Lego figure anywhere in the nature reserve to show where they would like to be when they visit. The distance $(\mathrm{cm})$ from the center of the photographs to the Lego figure is used to indicate the child's relative avoidance of the two animals. This task can also be employed with one animal (so that it is not measuring relative avoidance) or by using a triangular board to measure the relative avoidance for three types of animal. Finally, to access the physiological response system in Lang's model, the touch box task described earlier is sometimes adapted such that heart rate is measured while the child approaches the box.

The idea in this paradigm is, of course, that when children receive threat information about the stimulus their fear level across the three response systems will increase, whereas when children are given positive information their fear level will decrease. This main hypothesis was confirmed for the verbal-cognitive response system by Field et al. (2001) in a first test of the paradigm. In two experiments, children aged between 7 and 9 received either negative or positive information about an unknown monster doll. Results showed that fear-related beliefs about the monster doll changed significantly as a function of the verbal information. More precisely, threat information increased children's self-reported fear ratings, whereas positive information produced a decline. In later research, the "monsters" in the original paradigm have been replaced with novel real animals (Australian marsupials such as the quoll, quokka, and cuscus), mythical beasts, and novel social situations. In the following sections, these studies will be discussed in detail.

\section{Effects of Verbal Threat Information on the Fear Emotion}

Including the original study by Field et al. (2001), 17 research articles have been published describing a total of 22 experiments investigating the effects of threat information on childhood fear (see Table 1). All these studies were conducted with non-clinical children, which is an appropriate population for studying the effects of fearenhancing information in an experimental set-up. Most of the experiments measured fear toward novel animals and included a self-report measure of fear, and the vast majority of them (i.e., $88.9 \%$ ) has shown that self-reported fear can be increased when children are provided with threatening information about a stimulus or situation. At the same time, the results of most experiments $(71.4 \%)$ also indicated that self-report levels of fear can be decreased by means of positive information, and remain largely unchanged $(90.0 \%)$ when no information about the stimulus is provided. Altogether, it can be concluded that selfreport data have revealed that fear cognitions in children can be reliably manipulated via verbal information.

Although these studies address the subjective component of the verbal-cognitive response system in Lang's (1968) model, they say nothing about more automatic cognitions. This issue is problematic because children may simply be responding to the demands of the task. However, several studies have included measures that aim to assess more automatic cognitions by using tasks that measure implicit attitudes (e.g., Field and Lawson 2003; Field et al. 2008b; Lawson et al. 2007). In the current context, implicit attitudes refer to the phenomenon that fear-relevant stimuli will automatically activate associations in memory, which make it possible to quickly recognize their dangerousness (e.g., Fazio 2001). One measure that can be employed to assess implicit attitudes is the Implicit Association Task (IAT; Greenwald et al. 1998), which is based on the idea that it is easier to map two concepts onto a single response when those concepts are related in memory than when two concepts are unrelated (but see De Houwer et al. 2009). During the IAT, participants are presented with target words, control words, positive words, and negative words on the computer screen, and their main task is to rapidly categorize the words by pressing one of two response keys. When words refer to clearly associated categories and responses have to be given by the same response key, participants' response times should be faster compared to when non-associated categories share the same key. For example, a spider phobic individual will respond relatively fast when a target word (e.g., web) shares the same response key with a negative word (e.g., pain), but he will be relatively slow when the target word shares the same key with a positive word (e.g., joy), as it can be assumed that there will be stronger memory associations between spider-related and negative words and vice versa weaker associations between spider-related and positive words (see De Jong et al. 2003). Field and Lawson (2003) were the first to study the impact of threat information on children's performance during an IAT. Briefly, the results of their study indicated that children who had received threat information about a novel animal (the aforementioned quokka, quoll, and cuscus) displayed a stronger tendency to relate this animal to the negative words category. Similar results were obtained by Field et al. (2008b) who also employed the IAT, and by Lawson et al. (2007) who used an alternative index for measuring implicit attitudes, namely the Affective Priming Task (Fazio et al. 1986).

So far we have summarized the evidence that verbal threat information can alter the first of Lang's response systems; we now turn to studies that have looked at the 


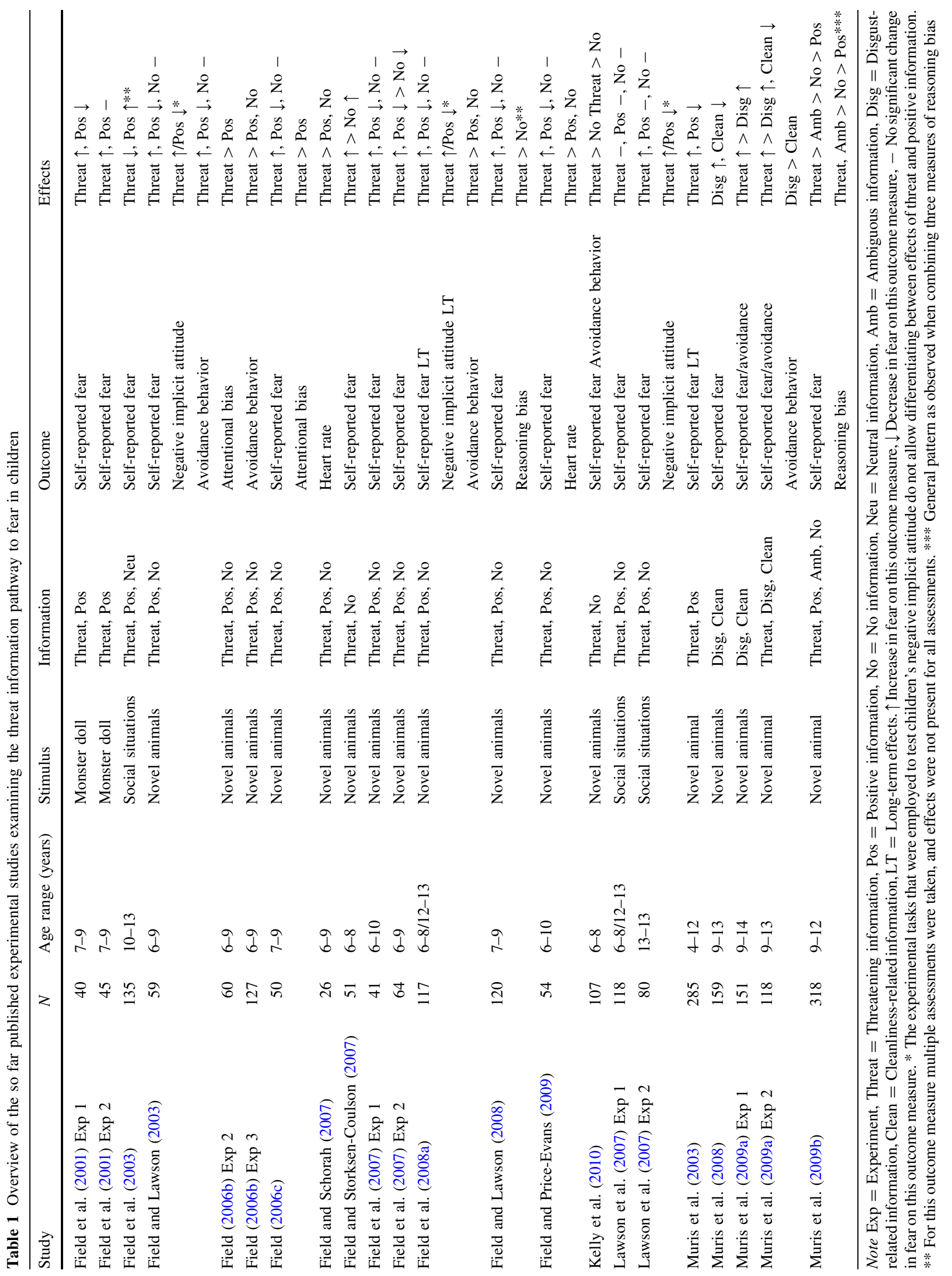


other two response systems, namely physiological responses and avoidance behavior. Two studies have looked at the effects of verbal information on heart rate as a physiological index of fear. Field and Schorah (2007) conducted an experiment during which 6- to 9-year-old children were provided with threat, positive, or no information about three unknown animals (i.e., Australian marsupials) in a counterbalanced order. Children then completed the aforementioned Touch Box Task during which their average heart rate was measured. The results showed that heart rates were significantly higher when children approached the box that presumably contained the animal for which they had received threatening information than when children got closer to the box containing an animal for which they had heard positive or no information, a finding that was replicated by Field and Price-Evans (2009).

There is also research examining the effects of threat information on the behavioral response system (see Table 1). In these experiments, children again first received either threatening, positive, or no information about novel animals. They were then asked to do the Touch Box Task (e.g., Field and Lawson 2003; Field et al. 2008b; Kelly et al. 2010) or the Nature Reserve Task (Field and Storksen-Coulson 2007) that have already been described. The results of these studies consistently demonstrate that children took longer to place their hand into the box (Touch Box), or placed the Lego figure at a larger distance from the animal (Nature Reserve) after they had received threatening information about it than when they had been given positive or no information. In other words, threat information appears powerful enough to induce mild levels of avoidance behavior in children.

\section{Long-Term Effects of Threat Information}

All the research that was discussed so far seems to warrant the conclusion that threat information promotes children's fear, at least in the short term. There are a few investigations, however, that explored whether verbal threat information has prolonged effects. In a first study, Muris et al. (2003) provided children aged 4-12 with either threatening or positive information about an unknown, dog-like animal, called "the beast." Children's self-reported fear was assessed at three points in time: before, directly after, and one week after the information about the beast was provided. Results showed that type of information changed children's fear of the beast in the predicted direction with threatening information increasing fear levels and positive information decreasing fear levels. Interestingly, this was not only the case directly after the experimental manipulation but also at one week follow-up.

In another investigation by Field et al. (2008b), children (aged 6-8 and 12-13 years) were exposed to threatening, positive, or no information about novel animals (the quoll, quokka, and cuscus). To study the short- and long-term effects of verbal information on explicit and implicit fear cognitions, children completed self-report scales of fear beliefs and the previously described IAT at various point in time: before and after the presentation of the information, and at subsequent 1-week, 1-month, 3-month, and 6-month follow-ups. Results demonstrated that verbal information produced the expected immediate effects: both explicit and implicit fear cognitions and avoidance behavior changed congruent with the information provided. Most important, the changes in explicit and implicit fear cognitions produced by the verbal information appeared to be fairly stable and persisted up to 6 months later. Another interesting feature of this study was that it tested the idea that children should be more susceptible to threat information at certain periods in their development. We mentioned earlier on that any model of childhood fear has to explain the apparent developmental pattern in normal fears that is believed to stem from evolutionary pressures that reflect the likely threats in our ancestors' environment. According to this theory, children's fears are animal-focused between the age of 6 and 8, which is perhaps indicative of evolution selecting for a fear-learning system that is primed to learn about animals at this age. Field et al. (2008b) tested this idea by comparing the effects of verbal threat information about novel animals in both 6- to 8-year-olds (who should be primed to learn about threatening animals) and 12- to 13-year-olds (for whom fear information should have a weaker effect). Their results showed virtually no difference in the effects of threat information on fear beliefs across the age groups; however, there was evidence that the underlying fear associations (as measured by the IAT) were somewhat weaker over the 6-month testing period in the older age group. These findings lend some support to the idea that verbal threat information might lead to stronger fear associations if the information pertains to a stimulus or situation that is developmentally significant to them.

All in all, available evidence indicates that verbal threat information produces fear effects to a stimulus for which children had no prior knowledge in all three of Lang's response systems. The other way around, positive information generally appears to have a fear-reducing effect for subjective reports, implicit cognitions and avoidance too. These effects are not just transient changes, but appear to reflect a long-term impact on children's fear. We now turn our attention to how verbal threat information interacts with other known anxiety-related phenomena and risk factors.

\section{Effects of Verbal Threat Information on Cognitive Biases}

Since the cognitive revolution in clinical psychology much research has been devoted to the study of information 
processing biases, which are thought to play an important role in the maintenance of psychological disorders such as phobias and anxiety disorders (e.g., Harvey et al. 2004). It is interesting to examine whether threat information has the potential to enhance such cognitive distortions because there is increasing evidence to indicate that these biases occur in fearful and phobic children (Muris and Field 2008). A first bias that has been investigated in this context refers to the tendency to display biased attentional processing of potentially threatening material (e.g., MacLeod et al. 1986). Two experiments by Field (2006b, c-Exp.2) have investigated whether threat information produces an attentional bias for a novel stimulus. For this purpose, children were provided with threatening, positive, or no information about novel animals, after which they completed a pictorial dot probe task. During this task, a series of two pictures are briefly presented on a computer screen: one picture is threat-relevant (i.e., a picture of the animal for which threatening information had been given), whereas the other picture is emotionally neutral or positive (i.e., a picture of the animal for which no information or positive information had been provided). Following the disappearance of the pictures, a small dot appears on the location previously occupied by one of the pictures. The latency to detect this probe provides an index of the extent to which a person's attention is directed toward the picture that just disappeared. Thus, faster latencies to detect a probe following threat-relevant pictures relative to neutral pictures would indicate an attentional bias toward threat. The results of both studies provided support for the idea that verbal threat information can create an attentional bias. That is, children responded faster when the dot appeared on the location of an animal for which they held negative beliefs than when the dot appeared on the location of an animal for which they had heard positive information (Field 2006b, c-Exp.2).

Another fear-related cognitive distortion that has been subjected to the effects of threat information is the reasoning bias, which pertains to the phenomenon that fearful or anxious people do not think about the world in a logical and objective way (Beck et al. 1985). There are various types of reasoning bias, one of which is confirmation bias that can be defined as the inclination to search for information that confirms the view that one holds. People often have convictions that boil down to conditional assumptions of the type "If $\mathrm{P}$, then $\mathrm{Q}$," with a certain stimulus $(\mathrm{P})$ being predictive of a particular outcome (Q), for example "If a dog barks, then he will bite" (see Hawton et al. 1989). In order to logically check the correctness of such an assumption, one should not only verify the rule (by ascertaining whether $\mathrm{P}$ is always followed by Q) but also falsify it (by assessing whether non-Q is never preceded by $\mathrm{P})$. However, in real-life people do not always think logically, and this is particularly true in case they are confronted with rules that signal danger for which they are inclined to mainly follow a verification strategy. A recent study by Muris et al. (2009b) demonstrated that 9- to 12year-old children who were provided with negative or ambiguous information about an unknown animal displayed a stronger tendency to rely on a verification strategy and a weaker inclination to employ a falsification strategy, when compared to children who received positive or no information about the animal (see also Remmerswaal and Muris in press). Clearly, these findings are in line with the notion that negatively tinted information can produce a fear-related confirmation bias in young people.

Similar findings have been obtained for a second type of reasoning bias, namely covariation bias. This bias is concerned with anxious people's tendency to overestimate the association between fear-relevant stimuli and aversive outcomes (e.g., Tomarken et al. 1989) and can be demonstrated by confronting participants with a series of pictures, some of which are fear-relevant while others are neutral. Following each picture one of three outcomes is presented, namely an aversive outcome, a neutral outcome, or no outcome. Fear-relevant and neutral pictures are equally often followed by each of the outcomes. After the series of slides, participants are asked to provide an estimate of the contingencies between slides and outcomes. Under these experimental conditions, fearful and anxious participants systematically overestimate the contingency between fear-relevant stimuli and negative outcomes. Field and Lawson (2008) have obtained evidence indicating that threat information might be a potent mechanism to induce this type of reasoning bias in youths. In that study, 7- to 9year-old children received threatening, positive, or no information about a novel animal, and then engaged in a causal learning task which measured covariation bias. More precisely, children viewed a series of slides of animals and following each slide they had to predict whether there would be a good outcome (i.e., a smiling face) or a bad outcome (i.e., a scared face). Results showed that while children normally underestimated the occurrence of bad outcomes in relation to the unknown animal (i.e., positivity effect), participants in the threatening information condition more often predicted bad outcomes so that they provided more accurate estimates of the contingency that they had experienced. The aforementioned study by Muris et al. (2009) also examined the effects of verbal information on covariation bias in children. For this purpose, 9- to 12-yearold children were first provided with either threatening, ambiguous, positive or no information about an unknown animal. Next, they were presented with imaginary scenarios: (1) being a subject in a scientific experiment during which pictures of the animal, flowers, and guns are shown, which are occasionally followed by a mild electric shock; 
(2) tasting new candy which are packed in a wrapper with a picture of the animal, a flower, or a gun, with some of the candy tasting very bad; and (3) participating in a marble contest in which you have to throw glass marbles which have inside a picture of the animal, a flower, or a gun from a distance in a hole. Some of the throws fail to hit the target. Following the scenarios, children were invited to provide estimates of the expected contingencies between the three stimulus types (i.e., animal, flower, gun) and the negative outcome (i.e., electric shock, bad tasting candy, missed throws). The results indicated that children who had received threatening and ambiguous information were more inclined to attribute negative consequences to the animal than children who had heard positive or no information, which of course supports the idea that verbal information with a negative content can produce an $a$ priori covariation bias in children.

Thus, while it is generally assumed that the genetically based personality disposition of neuroticism enhances children's vulnerability to display biased information processing (Muris and Field 2008; Vasey and MacLeod 2001), the findings of these studies indicate that learning via threatening information also seems to be involved in the acquisition of fear-related cognitive biases.

\section{Contextual Variables in the Susceptibility to Threat Information}

Personality has long been considered important in the acquisition of fear. For example, Eysenck (1967) assumed that personality traits such as neuroticism and introversion, which are associated with a proneness to experience emotional problems, are grounded in genetically determined individual differences in the arousability of various brain systems. Individuals who score highly on both neuroticism and introversion are believed to be more likely anxious: anxiety as a trait is viewed as bisecting the neuroticism-introversion space in Eysenck's two-factor personality model, retaining a closer connection to neuroticism than introversion (Gray and McNaughton 2003). The basic idea is that in some individuals certain brain areas are too easily aroused, which has not only direct (e.g., arousal effects on attention) and indirect (e.g., avoidance of stimuli and situations) behavioral consequences, but also influences learning processes such as fear conditioning (Gray 1981; Matthews et al. 2003). Gray (1987, 1988) suggested that trait anxiety was governed by a specific brain system, the behavioral inhibition system (BIS). The anatomical substrate of the BIS is the septohippocampal system, which controls anxiety in relation to relevant environmental cues. The BIS is associated with sensitivity to novelty cues, non-reward and punishment.
Many temperament models of anxiety are based on constructs that are underpinned by the BIS. For example, temperamental vulnerabilities to anxiety such as "negative emotionality" (Tellegen 1985), "negative affect" (Clark and Watson 1991), "behavioral inhibition" (Kagan et al. 1987), and "fear" (Rothbart et al. 2000) despite their conceptual differences are all believed to predict anxiety symptomatology and reflect outputs of the BIS. As such, they are all, arguably, different conceptualizations of trait anxiety (Field 2006b). It follows from a variety of temperament models then that individual differences in the sensitivity of the BIS determine trait anxiety (Clark and Watson 1991; Gray 1987, 1988; Gray and McNaughton 2003). As such, trait anxiety (or BIS sensitivity) should moderate the effect that verbal threat information has on fear.

This issue was directly addressed in a study by Field (2006b) who got children aged 6-9 years to complete an age-downward version of Carver and White's (1994) BIS scale and then received either threatening, positive or no information about unknown animals. Following this, children's fear levels were assessed by means of the Touch Box Task (described previously) and a pictorial dot probe task as an index of attentional bias. The results showed that BIS sensitivity not only promoted avoidance behavior of animals associated with the threatening information, but also facilitated a fear-related attentional bias to animals for which children had heard such threat information. These findings provide support for the idea that threat information has greater impact on children who have an inherent proneness to acquire fears. In a related study, Field and Price-Evans (2009) replicated this experiment but used heart rate during the touch box task as a measure of Lang's physiological fear response system. They found that selfreported BIS sensitivity moderated the effect that threat information has on heart rate during an approach task. In combination, these studies show that trait anxiety facilitates the effect of verbal threat information on all three response systems of fear: cognition, avoidance, and physiological responses. However, it is worth noting that several studies (e.g. Field and Lawson 2003; Field et al. 2008b) that have measured children's general fearfulness using the FSSC-R (Ollendick 1983) have indicated that a child's normative fears do not significantly moderate the impact of verbal threat information.

Another individual difference variable that may moderate the influence of verbal information is gender, because females are more prone to anxiety than males (Craske 2003). Most experimental studies on verbal information pathway have investigated the effects of information with a clearly positive or negative content, and in general this research has demonstrated that boys and girls are equally 
affected by these types of information (e.g., Field and Lawson 2003). Interestingly, one investigation that provided children with ambiguous verbal information about a novel animal revealed a moderating influence of gender (Muris et al. 2009). That is, results demonstrated that whereas both genders responded in a similar way to negative and positive information, girls clearly displayed higher fear levels than boys after hearing the ambiguous information. This finding suggests that when information about a stimulus is less clear-cut, girls may be more prone to show fear responses compared to boys. Note that this finding is in keeping with the common observation that girls exhibit higher levels of fear than boys (Craske 1997; Muris 2007), which may well have to do with the fact that the expression of fear is more in agreement with the feminine than with the masculine gender role (Ollendick et al. 1995). Obviously, additional research is required to further explore gender differences in children's reactions to ambiguous information, in particular studies that also include non-self-report indices of fear.

A final potential moderating influence on the verbal information pathway that has been explored is the parenting environment within which the child has developed. Parenting styles have long been acknowledged as an important predictor of child anxiety (see McLeod et al. 2007, for a recent review). However, there is some inconsistency in the literature as to which parenting styles predict anxiety and to how much variance in anxiety they actually explain. This inconsistency has led Field et al. (2008a) to theorize that parental practices interact with other learning experiences such as verbal threat information. Essentially, there are two possibilities. The first is that anxious parents transmit their fears through pathways such as verbal information (Hadwin et al. 2006); in effect the verbal feedback that they give their children "trains" them to think and behave anxiously (Field and Lester in press). A prediction from this idea is that anxious parents differ in the way that they transmit information verbally to their children. We will explore this prediction in due course. The second possibility is more pertinent to the current discussion; that is that certain parenting styles create a background context within which verbal threat information is processed by the child. In other words, being bought up in an anxiogenic environment makes you more susceptible to verbal threat information.

This later idea has been explored in two studies. In the first, Field et al. (2007) showed that there were two moderating influences on the effect of verbal threat information about a novel animal on anxiety cognitions in 6- to 9-yearold children: (1) a punitive maternal parenting style; and (2) a greater number of negative interactions with fathers (but not mothers). Price-Evans and Field (2008) extended this study to look at the effects on the physiological response system. They found that a neglectful maternal parenting style interacts with the verbal information pathway to affect the child's physiological response to verbal threat information. These results are, in a sense, inconsistent in that no particular parenting style clearly emerged as interacting with verbal threat information. However, notwithstanding the need for more research, these two studies do show that parenting and the child's everyday environment are a context within which children process verbal threat information. If that context is negative then threat information is likely to have a greater impact.

Although clearly more research is needed to further explore these issues, what evidence there is suggests that some children may be more prone to the detrimental effects of verbal threat information than others. First, personality characteristics (e.g., trait anxiety or BIS sensitivity) moderate the effects of threat information, and a female gender increase young people's susceptibility to ambiguous information. Second, the context in which the child places the threat information they receive might be an important moderator of the impact that the information has: although more work is needed, it seems to be the case that a negative home environment makes children more susceptible to threat information.

\section{The Source of Threat Information}

Recall that Rachman's (1977) original assumption was that information transmission during childhood "is carried on by parents and peers in an almost unceasing fashion." An overview of the research so far, however, quickly reveals that few studies have actually investigated this notion. Field et al.'s (2001) initial study examined whether the source of verbal information has any effect on changes in children's fear beliefs. In one of their experiments, children aged 7-9 were presented with information about two unknown monster dolls. The information was either provided by their teacher, an adult stranger, or a peer. Results demonstrated that the verbal information changed children's fear beliefs, but that this was only the case when the information was provided by an adult. Although this suggests that transmission via an adult person is more important than transmission via peers, it should also be borne in mind that this may also have to do with children's age and the type of stimulus about which the information is given. For example, it may well be the case that when an adolescent first hears about the danger of a novel drug, the impact of the information will be larger when the information is provided by a peer than when it is given by a parent. This is borne out by some unusual findings, which will be discussed later, showing that verbal information about social situations can be more powerful when presented by a peer (Field et al. 2003). 
We mentioned earlier that verbal threat information might act as a pathway through which anxious parents transmit their fears to their children. If this is the case then you would expect anxious parents to differ in the way that they use verbal information about novel stimuli. One obvious way to test this is to use the verbal threat information paradigm but incorporating parents into the procedure. In an ongoing program of research, Field et al. (2008c) asked parents of 6- to 10-year-old children to read scripts containing an equal amount of positive, negative, and neutral information about novel animals (the aforementioned marsupials). Subsequently, these parents were instructed to tell their children about these animals. Initial results showed only modest correlations between parental trait anxiety and the negativity of the verbal information that they passed onto their child. However, it remains to be seen what qualitative differences emerge in a more detailed analysis of the parent-child interactions.

More promising results have emerged in a recent study by Muris et al. (in press). Children aged 8-13 were first presented with the picture of an unknown animal and then evaluated it on a fear beliefs scale. Next, children's mothers were also shown the picture of the unknown animal and silently provided with either negative, positive, or ambiguous information about it. Following this, parents were given several open-ended vignettes describing a series of confrontations with the animal (e.g., encountering the animal in the park) with the instruction to tell their children what would happen in these situations. Finally, children's fear beliefs were assessed again. Data were in keeping with the idea that children's fears can be influenced via information provided by the mother. That is, parents who had received threat information about the animal provided more negative and threatening narratives about the animal and hence installed higher levels of fear beliefs in their children than parents who had received positive information. Interestingly, in the case of the ambiguous information condition, it was found that the transmission of fear was largely dependent on parents' trait anxiety levels. More precisely, high trait anxious mothers told more negative stories about the unknown animal, which in turn produced higher fear levels in the children. These effects seemed somewhat stronger than those of Field et al. (2008c), which might reflect the more ambiguous nature of the information in Muris et al.'s (in press) study (i.e., in Field et al.'s study the information was a mix of positive, negative, and neutral statements).

To sum up, there is some evidence that the source of verbal threat information can make a difference. In younger children (and when the information is about animals), adults seem to have more impact than peers (although this effect could reflect the relatively superior verbal fluency of adults). Clearly, a great deal more research is needed to explore how the importance of the source of information varies across ages and situations. As the primary source of information, the verbal information from parents should be particularly important. This issue is only just beginning to be researched but there is encouraging support for the idea that parents may be important in the formation of childhood fears via this pathway. Future research needs to attempt to unpick the complex nature of these parent-child interactions, and also eventually try to understand not just how anxious parents use verbal information but also how anxious children influence what their parents choose to tell them.

\section{The Stimulus About Which Information is Given}

In the vast majority of the experiments that we have discussed so far, threat information was employed to enhance fear of an unknown animal for which children did not possess any prior information. However, a few other studies have attempted to induce fears in children of other situations via threat information. For instance, two investigations have explored the effects on children's explicit and implicit fear beliefs about social events. In the first of these, Field et al. (2003) gave 10- to 13-year-olds information (using stories) about three social situations commonly associated with social fears in the clinical literature: eating in public, meeting a new group of children, and speaking in public. However, unlike experiments that used novel animals as a stimulus, the results here showed an inconsistent pattern: a change in fear-related beliefs depended on both the particular situation, and on who was presenting the information. Threat information resulted in decreased fear beliefs, while positive information resulted in increased fear beliefs about public speaking when presented by a peer. A pessimistic conclusion from this study is that fear information is not, in general, a viable pathway for acquiring social fear beliefs. However, the authors suggested that the social situations in this paradigm may have varied in their novelty and so children would possess prior expectancies and beliefs about each situation. Unlike the animal paradigm, the threat information had to battle against already entrenched beliefs. Also, the peculiar finding that threat information had the opposite effect than expected for public speaking when presented by a peer was explained in terms of social comparison theory: the children identified with the main characters in each story and made downward comparisons to them. As such, when the main character in the story did badly (threat information) children believed that they would do better in the same situation, which decreased their fear beliefs.

In a subsequent study, Lawson et al. (2007) tried to refine this paradigm by using less commonly experienced social situations (e.g., meeting a celebrity; Experiment 1), 
and by including a measure of implicit attitudes (i.e., an affective priming task; Experiment 2). In Experiment 1 in which the verbal information took the form of a specific vignette about some unknown person's experience (as in Field et al. 2003), no significant effects were found. However, in Experiment 2, in which verbal information was presented in the form of multiple opinions and attitudes expressed by groups of adults or children, significant changes in fear-related beliefs about social situations measured both explicitly and implicitly were found.

Although these experiments provide some evidence that verbal threat information can have an impact across stimuli other than animals, the data are much weaker. This weakness could reflect the novelty of the stimuli in the animal paradigm compared to the social situations: obviously, threat information has little to add when children have already developed clear expectations about what they have to fear (or not to fear) in these situations. Nevertheless, more research is needed to mark out the parameters of the verbal threat information pathway and especially to test whether novelty is important, and the precise impact of prior experience with a stimulus.

\section{Other Types of Verbal Information}

So far we have discussed mainly the effects of overtly threatening information on a child's fear emotion. However, the results of the study by Muris et al. (2009b) that we discussed earlier clearly indicate that verbal information does not need to be explicitly threatening to install fear in children. In that study, ambiguous information about a novel animal also resulted in heightened levels of fear beliefs and reasoning bias. This result can best be explained by assuming that the ambiguous information triggers a "better safe than sorry" strategy. That is, when an individual is confronted with an unknown stimulus for which he receives equivocal information with a potential negative tone, it is probably most adaptive to expect and prepare for the worst (Gilbert 1998).

Disgust-related information is another type of information that may have fear-enhancing effects. Briefly, disgust can be defined as a basic emotion that is characterized by a desire to distance oneself from contamination and revulsion-eliciting stimuli (Olatunji and Sawchuck 2005). As such, disgust is different from fear as in the latter emotion the motive to stay away from a stimulus is more strongly guided by the imminent threat of physical harm. Research has shown that disgust is clearly associated with childhood phobias, and in particular animal phobias (e.g., De Jong and Muris 2002; Muris et al. 2008c). To conceptualize the role of disgust in animal phobias, Matchett and Davey (1991) have put forward a disease-avoidance model, which proposes that the focus of the fear in this type of phobias is related to the unwanted contact with a disgusting stimulus rather than to physical harm. In this view, it is particularly important how an animal is mentally represented (see Huijding and De Jong 2007), and therefore it would be interesting to study whether the provision of verbal disgustrelated information has fear-enhancing effects. A first study that has addressed this issue was conducted by Muris et al. (2008b) who presented 9- to 13-year-old children with disgust-related and cleanliness-related information about unknown animals. Before and after the information, beliefs of disgust and fear regarding the animals were assessed. Results showed that disgust-related information not only induced higher levels of disgust but also increased children's fear beliefs in relation to these animals. Further, cleanliness-related information decreased levels of disgust and resulted in lower levels of fear. In follow-up research by Muris et al. (2009a), these results were largely replicated: that is, disgust-related information enhanced children's fear (although less than threatening information) and this effect was even demonstrated on a behavioral avoidance test.

While Field et al.'s (2001) paradigm has been predominantly employed to investigate the effects of threatening information on children's fears, it is clear that the provision of ambiguous or other types of negative information (e.g., disgust-related information) may also be relevant in this context. Clearly, this is a topic that requires further research.

\section{Summary of the Research on Effects of Threat} Information on Childhood Fear

Studies examining the effects of threat information via media exposure or by means of retrospective child- and parent-reports on the origins of anxiety phenomena have yielded suggestive evidence indicating that this type of learning experience may be involved in the etiology of childhood fears. More convincing support for the role of threat information has been obtained after the introduction of an experimental paradigm which made it possible to study the causal status of this pathway to childhood fear under controlled conditions (Field et al. 2001). In short, investigations that employed this experimental set-up have clearly demonstrated that changes in all three of Lang's (1968, 1985) fear response systems (cognitive, behavioral, and physiological) can be produced by giving children threatening or otherwise (potentially) negative information about a stimulus. These effects can last up to six months. As such, Rachman's (1977, 1991) original notion that childhood fears can be installed via this route has been substantiated. The changes found in physiological measures and reaction-time based attitude measures suggest that these findings are not simply children responding to task demands. 
In addition to these basic findings, several contextual variables have been identified that moderate the effect that threat information has. The child's trait anxiety appears to enhance the effect of verbal information, as does his domestic environment (i.e., the parenting style adopted by parents). Girls also seem particularly vulnerable to interpreting ambiguous information in a threatening way.

However, although the effects of threat information obtained in experimental research are fairly robust in terms of statistical significance and the effect sizes obtained, they are fairly small in terms of absolute fear levels (i.e., children do not exhibit levels of fear anywhere close to clinical levels). Although this is of course good from an ethical point-of-view, it remains to be seen to what extent verbal threat information transmission represents a relevant mechanism to explain the acquisition of more severe fears or even phobias. To illustrate this point, we saw earlier that threat information appears to be relatively ineffective at changing fear beliefs about situations about which children have pre-existing expectations, such as social situations. In view of these points, a cynic might wonder whether threat information transmission really represents an important pathway to childhood fears and phobias. However, the role of this learning mechanism should not be underestimated because it is extremely unlikely that fears develop along single pathways, but instead they originate as a result of complex interactions between new learning events, past experience, and contextual variables (Muris 2007). For example, we have seen that trait anxiety facilitates the effects of threat information, as does the child's rearing environment. In much the same way that the verbal information pathway interacts with temperament and environment, it will interact with other learning pathways. In the next section, we explore the probable mechanisms that underlie the verbal information pathways and look at its interaction with other pathways to fear.

\section{Mechanisms of Threat Information}

\section{Associative Learning}

How does threat information have its influence on the formation of childhood fears? Field (2006a) has proposed that "associative learning is the prime mechanism to explain how fear information operates" (p. 868). To really understand this process, one has to keep in mind that associative learning (and in the current context fear conditioning) is no longer conceptualized as reflex-like stimulus-response learning but instead should be viewed as a process during which individuals form an association in memory (i.e., learn) that a certain stimulus (the CS) is likely to predict the occurrence of an aversive outcome (the
US), which in turn under some conditions will elicit a conditioned response (the CR). In other words, fear learning has to do with forming an association between a neutral stimulus and a noxious outcome (see also Dadds et al. 2001). It is also worth remembering that these stimuli and outcomes need not be real. Field (2006a) cites evidence that suggests that associative learning can operate on mental representations. So, for example, if a child imagines an animal and then gets a fright, the association between that animal and fear will be formed or strengthened. The same is true if a child were to see an animal and then imagine something traumatic. Field, therefore, suggests that the process underlying all of Rachman's pathways is likely to be simple associative learning. In the case of verbal threat information, the information evokes a representation of the threat with all of its associated qualia that becomes associated (or the association is strengthened) in memory with whatever the information was about. A simple example would be that a child sees a dog in the park, while his mother says "Stay near me, that dog might bite." Field would argue that the information evokes a conceptual representation of threat and in doing so the associative connection between the concepts of "dogs" and "threat" is strengthened. Subsequent evocations of the mental representations of dogs would, therefore, become more likely to also evoke a representation of threat and the behaviors and feelings driven by that representation.

There is little existing evidence to support or refute Field's (2006a) theory. However, we believe that it is a powerful framework around which to structure future research and theory (even if it turns out not to be true). For example, by conceptualizing threat information as operating through an associative network, it is possible to explain various phenomena and to make predictions about what factors should mitigate or exacerbate the verbal information pathway. For example, the possibility that novelty is important in producing fear responses through verbal information is consistent with models of associative learning which suggest that prior exposure to a stimulus retards learning (latent inhibition) and that learning about unusual events is more powerful than focusing attention on known relationships in the environment (e.g., see the model described by Pearce and Hall 1980).

\section{Interactions With Other Pathways to Fear}

Irrespective of the mechanism underlying the effects of threat information, this pathway is assumed to feed into other processes such as direct conditioning which is considered as another important etiological factor in contemporary models of fear acquisition (Davey 1997; Mineka and Zinbarg 2006; Muris 2007). It is plausible that threat information transmission interacts with direct learning 
experiences to produce fear reactions. That is, children do not enter daily events as tabula rasa; they instead bring with them information about certain stimuli and situations, which may ultimately determine their level of fear. For example, children are likely to startle when unexpectedly confronted with a barking dog, but they might panic when noticing that the dog is a pitbull terrier which are known to be quite aggressive. Although direct conditioning lies at the heart of current fear acquisition models, verbal information is featured as a pathway that influences this conditioning process. Whereas Field (2006a) entertains the possibility that verbal information can directly affect the formation or strength of stimulus-threat associations, these other models implicitly assume that some direct traumatic experience is necessary. They may well be correct that clinical fears require such experiences, but all of the models acknowledge the power of verbal information to influence the process.

There are two ways through which threat information may affect direct conditioning. First of all, verbally transmitted warnings such as "Don't touch that," "Be careful of that," or "That animal might bite" may create an expectancy that a stimulus (in this case an animal) is likely to be followed by something bad happening. These expectancy evaluations (as Davey 1997 labels them) will lead to a stronger (and faster) association being formed if something bad really does happen when the animal is encountered. Davey makes no assumption about what these expectations are, but Field (2006a) would assume that they are associations that are then strengthened by the direct conditioning experience.

One study supports this idea in children. Field and Storksen-Coulson (2007) conducted an experiment during which they first provided 6- to 8-year-old children with either threatening or no information about a novel animal, and then exposed them to a simulated direct negative encounter with that animal (i.e., children were asked to touch the animal in a closed box that suddenly started to move). Findings showed that the threatening information (without a subsequent negative experience) and the direct negative experience (without prior information) had comparable fear-enhancing effects. However, the combination of the two pathways (verbal threat information followed by a direct negative experience) clearly yielded a magnified effect. Most important, as predicted by Davey's (1997) model, the extent to which the verbal information changed fear beliefs (expectancies) fully mediated the effect that the direct negative experience had.

The second way in which verbal information might affect direct conditioning is by enhancing the aversiveness of the US, a phenomenon that is known as "US inflation" (Davey et al. 1993). US inflation can be illustrated by the following clinical case: "Michael is a 10-year-old who applied for behavior therapy because of a severe dog phobia. Currently, he is so afraid of dogs that he does not dare to go out on the street alone. Only because one of his parents accompanies him every day, he is still able to visit school. His phobia started about a year ago after he was attacked by a stray dog. Michael was not seriously injured and initially he was not particularly frightened. However, this changed some two weeks after the incident, when Michael learned from his grandfather that many stray dogs suffer from rabies, a disease that can be transmitted to humans by bite, and which, if left untreated, can cause a painful death. From that moment on, Michael was extremely fearful of dogs and started to exhibit persistent avoidance behavior" (Muris 2007; p. 75). This case exemplifies how verbally transmitted information increased the aversiveness of the US (that was initially experienced as rather mild) and how this information eventually led to phobic fear for the CS (i.e., dogs) supposedly by activating a representation of an inflated US.

One other study has attempted to look at how pathways fear to interact. This study looked at the effect of verbal information on the vicarious learning pathway rather than direct conditioning; however, vicarious learning is, arguably, underpinned by the same associative learning mechanism as direct conditioning experiences (see Askew and Field 2008 for a review) and so this experiment might offer some insights into how verbal information affects other associative fear learning. The study in question (Askew et al. 2008) used verbal information before, during, or after vicarious learning experiences. Broadly speaking, they replicated Field and Storksen-Coulson's (2007) results in that prior verbal threat information significantly facilitated the effects of a negative modeling experience on children's fear beliefs. However, contrary to expectations, verbal information after vicarious learning did not seem to enhance fear learning.

\section{Summary}

To summarize, the effect that verbal threat information has may well be to form or strengthen associations between a stimulus or situation and some representation of threat (a CS-US association). Available data suggest that verbal threat information certainly creates expectancies about the likely outcomes of a conditioning episode (be that direct conditioning or vicarious learning) and that these expectations mediate the effect that the conditioning episode has on fear. However, it is not clear that verbal information is successful in revaluing vicarious learning experiences, and, as yet, no data are available to see the effect in children of revaluing the conditioning experience using verbal threat information. We also propose that verbal threat information not only interacts with other associative learning 
experiences, but in itself operates through this mechanism: that is, it has a direct effect on the associations formed between a stimulus and a negative outcome or representation of threat (Field 2006a). However, this idea has yet to be tested empirically.

Further, although we focused our present discussion on the role of threat information in interaction with conditioning and modeling, it needs to be acknowledged that many other factors may be involved in the development of childhood fears. In their review, Muris et al. (2002) have emphasized that the child's developmental level, stimulus characteristics (e.g., novelty, unpredictability), early experiences with uncontrollable events, and genetically based vulnerability also play a critical role. This means that to fully understand why some children develop problematic fears while others don't, one should not only pay attention to threat information and other learning experiences but take all these variables into account (Muris 2007).

\section{Implications for Intervention and Prevention}

In the previous sections, we have primarily focused on the detrimental effects of verbal threat information in the formation of childhood fears. As an aside it was also noted that positive information may have fear-reducing effects, which is interesting from a therapeutic point-of-view. Of course, information-giving is an integral part of currently employed cognitive-behavioral interventions (Ollendick and King 1998), which have proven to be highly effective for treating youths with phobias and other anxiety disorders (e.g., Kendall et al. 2004; for a review see James et al. 2005). That is, during such interventions, children are frequently presented with positively tinted, realistic information in order to correct their threat-biased views of the stimuli and situations that they fear. Although the provision of such information seems to be a sensible first step for initiating therapeutic change, the power of positive information should not be overestimated. The research that was described earlier clearly indicates that positive information has a suppressing effect on children's fears of novel stimuli (see Table 1). However, the few experiments that explored the effects of verbally transmitted information on children's evaluation of well-known (i.e., social) situations demonstrated that positive information did not produce substantial decreases in fear (Field et al. 2003; Lawson et al. 2007).

However, one study has directly tested the utility of verbal information in reversing the effects of fear beliefs and avoidance acquired through verbal information (Kelly et al. 2010). In this experiment, non-clinical children aged 6 to 8 were given verbal threat information about novel animals, and their fear beliefs and avoidance during a touch box task changed accordingly. Subsequently, children received one of three "interventions:" positive verbal information, positive modeling (the experimenter approached the touch box and smiled as she placed her hand in the box), or no intervention. Fear beliefs and avoidance were again measured after the "intervention." The results showed that fear beliefs and avoidance persisted when no intervention was used, but reduced after positive information and modeling. One interesting finding was that for self-reported fear beliefs, positive verbal information was a more successful "intervention" than modeling, but for behavioral avoidance positive modeling and verbal information had similar effects. This experiment is the first to look at how verbal information might be used as a corrective tool. However, it is worth noting that the study has limited implications for clinical work because it merely looked at how a short burst of positive information could correct a small amount of threat information provided to non-clinical children rather than trying to alter long-established fears that have developed through complex interactions between the fear pathways. Thus, it seems really important to study the fear-reducing effects of verbal information in clinically referred children who suffer from real phobic complaints.

Positive verbal information might also be useful as a preventive strategy. Of particular relevance in this context is the concept of latent inhibition, which refers to the phenomenon that a large number of neutral or positive experiences with a stimulus or situation (the CS) will hinder the subsequent formation of a strong link between this CS and an US (Lubow 1973). When translating this principle to fear acquisition via the verbal information pathway, it may be advisable to regularly expose children to positive information about stimuli and situations so that an eventual exposure to threat information has no detrimental impact. From a preventive viewpoint, it might be worthwhile to inform parents on this learning principle as they are most likely to be the prime messengers of information about the world. The aforementioned study by Muris et al. (in press) further suggests that one should especially focus on the high anxious parents and employ some kind of cognitive intervention to teach them to make less threatening interpretations and to provide their children with more positive information about ambiguous stimuli and situations (see Lester et al. 2009).

\section{Summary and Future Directions}

As current theories assume that childhood fears form the basis for many of the specific phobias (Craske 2003; Muris 2007), research on the factors that contribute to the formation and exacerbation of these phenomena is certainly important. In his three pathways theory, Rachman (1977, 1991) postulated that besides the pathways of conditioning 
and modeling, threat information transmission should be regarded as a third route along which fears and phobias in children can be acquired. The present research overview indicates that there is clear support for the notion that the verbal provision of threat information may have fearenhancing effects in children, with the most convincing evidence for a causal link coming from studies that employed Field et al.'s (2001) experimental paradigm for examining the effects of verbal information prospectively. One can argue that the effects documented in this research were fairly small, and that hence the contribution of threat information transmission in the acquisition of childhood fears and phobias is at best modest. Meanwhile, a proper understanding of the basic mechanism by which threat information exerts its influence on fear (i.e., associative learning), and an acknowledgment of the fact that this type of learning is so frequently occurring during the development of youth, may qualify this criticism.

However, to definitively deal with such critical notes, we think that the time has come for researchers to test Field et al.'s paradigm under more ecologically valid conditions. Nice examples are the studies by Field et al. (2008c) and Muris et al. (in press), which made an attempt to mimic the basic process of information transmission from parents to their children, but obviously other directions are also possible. For instance, children could be provided with a mix of information about a novel stimulus, which is of course more in keeping with how this type of learning actually takes place in daily life. Further, it would be interesting to experimentally document the effects of positive information, especially as a protective mechanism via the process of latent inhibition. Finally, the experimental studies so far have mainly focused on the effects of verbal threat information about novel animals and predominantly relied on samples of children in the primary school age (i.e., 6-12 years). In the years to come, it may be worthwhile to investigate the effects of informational learning for other stimuli and situations and in different age groups (e.g., preschoolers and adolescents). With this research agenda, the effects of threat information can be further explored, which will give us a better picture of the role of this learning mechanism in the acquisition of childhood fears.

Open Access This article is distributed under the terms of the Creative Commons Attribution Noncommercial License which permits any noncommercial use, distribution, and reproduction in any medium, provided the original author(s) and source are credited.

\section{References}

American Psychiatric Association. (1994). Diagnostic and statistical manual of mental disorders (4th ed.). Washington, DC: American Psychiatric Association.
Askew, C., \& Field, A. P. (2008). The vicarious learning pathway to fear 40 years on. Clinical Psychology Review, 28, 1249-1265.

Askew, C., Kessock-Philip, H., \& Field, A. P. (2008). What happens when verbal threat information and vicarious learning combine? Behavioural and Cognitive Psychotherapy, 36, 491-505.

Bauer, D. H. (1976). An exploratory study of developmental changes in children's fears. Journal of Child Psychology and Psychiatry, 17, 69-74.

Beck, A. T., Emery, G., \& Greenberg, R. L. (1985). Anxiety disorders and phobias: A cognitive perspective. New York: Basic Books.

Buijzen, M., Van der Molen, J. H. W., \& Sondij, P. (2007). Parental mediation of children's emotional responses to a violent news event. Communication Research, 34, 212-230.

Cantor, J. (1998). Mommy I'm scared: How TV and movies frighten children and what we can do to protect them. San Diego, CA: Harcourt Brace.

Cantor, J., \& Nathanson, A. I. (1996). Children's fright reactions to television news. Journal of Communication, 46, 139-152.

Carver, C. S., \& White, T. L. (1994). Behavioral inhibition, behavioral activation, and affective responses to impending reward and punishment: The BIS/BAS scales. Journal of Personality and Social Psychology, 67, 319-333.

Clark, L. A., \& Watson, D. (1991). Tripartite model of anxiety and depression: Psychometric evidence and taxonomic implications. Journal of Abnormal Psychology, 100, 316-336.

Comer, J., Furr, J. M., Beidas, R. S., Babyar, H. M., \& Kendall, P. C. (2008). Media use and children's perceptions of societal threat and personal vulnerability. Journal of Clinical Child and Adolescent Psychology, 37, 622-630.

Comer, J. S., \& Kendall, P. C. (2007). Terrorism: The psychological impact on youth. Clinical Psychology: Science and Practice, 14, 179-212.

Craske, M. G. (1997). Fear and anxiety in children and adolecents. Bulletin of the Menninger Clinic, 61(Suppl A), A4-A36.

Craske, M. G. (2003). Origins of phobias and anxiety disorders. Why more women than men? Oxford: Elsevier.

Dadds, M. R., Davey, G. C. L., \& Field, A. P. (2001). Developmental aspects of conditioning processes in anxiety disorders. In M. W. Vasey \& M. R. Dadds (Eds.), The developmental psychopathology of anxiety (pp. 205-230). New York: Oxford University Press.

Davey, G. C. L. (1997). A conditioning model of phobias. In G. C. L. Davey (Ed.), Phobias: A handbook of theory, research and treatment (pp. 301-322). Chichester: Wiley.

Davey, G. C. L., De Jong, P. J., \& Tallis, F. (1993). UCS inflation in the aetiology of a variety of anxiety disorders: Some case histories. Behaviour Research and Therapy, 31, 495-498.

Davies, P., Lee, L., Fox, A., \& Fox, E. (2004). Could nursery rhymes cause violent behaviour? A comparison with television viewing. Archives of Disease in Childhood, 89, 1103-1105.

Davis, T. E., \& Ollendick, T. H. (2005). Empirically supported treatments for specific phobia in children: Do efficacious treatments address the components of a phobic response? Clinical Psychology: Science and Practice, 12, 144-160.

De Houwer, J., Teige-Mocigemba, S., Spruyt, A., \& Moors, A. (2009). Implicit measures: A normative analysis and review. Psychological Bulletin, 135, 347-368.

De Jong, P. J., \& Muris, P. (2002). Spider phobia: Interaction of disgust and perceived likelihood of involuntary physical contact. Journal of Anxiety Disorders, 16, 51-65.

De Jong, P. J., Van den Hout, M. A., Rietbroek, H., \& Huijding, J. (2003). Dissociations between implicit and explicit attitudes toward phobic stimuli. Cognition and Emotion, 17, 521-545.

Di Nardo, P. A., Guzy, L. T., Jenkins, J. A., Bak, R. M., Tomasi, S. F., \& Copland, M. (1988). Etiology and maintenance of dog fears. Behaviour Research and Therapy, 26, 241-244. 
Doogan, S., \& Thomas, G. V. (1992). Origins of fear of dogs in adults and children: The role of conditioning processes and prior familiarity with dogs. Behaviour Research and Therapy, 30, 387-394.

Ehlers, A., Hofmann, S. G., Herda, C. A., \& Roth, W. T. (1994). Clinical characteristics of driving phobia. Journal of Anxiety Disorders, 8, 323-339.

Eley, T. C., \& Gregory, A. M. (2004). Behavioral genetics. In T. L. Morris \& J. S. March (Eds.), Anxiety disorders in children and adolescents (pp. 71-97). New York: Guilford.

Eysenck, H. J. (1967). The biological basis of personality. Springfield, IL: Thomas.

Fazio, R. H. (2001). On the automatic activation of associated associations evaluations: An overview. Cognition and Emotion, $15,115-141$.

Fazio, R. H., Sanbonmatsu, D. M., Powell, M. C., \& Kardes, F. R. (1986). On the automatic activation of attitudes. Journal of Personality and Social Psychology, 50, 229-238.

Field, A. P. (2006a). Is conditioning a useful framework for understanding the development and treatment of phobias? Clinical Psychology Review, 26, 857-875.

Field, A. P. (2006b). The behavioral inhibition system and the verbal information pathway to children's fears. Journal of Abnormal Psychology, 115, 742-752.

Field, A. P. (2006c). Watch out for the beast: Fear information and attentional bias in children. Journal of Clinical Child and Adolescent Psychology, 35, 431-439.

Field, A. P., Argyris, N. G., \& Knowles, K. A. (2001). Who's afraid of the big bad wolf: A prospective paradigm to test Rachman's indirect pathways in children. Behaviour Research and Therapy, 39, 1259-1276.

Field, A. P., Ball, J. E., Kawycz, N. J., \& Moore, H. (2007). Parentchild relations and the verbal information pathway to fear in children: Two preliminary experiments. Behavioural and Cognitive Psychotherapy, 35, 1-14.

Field, A. P., Cartwright-Hatton, S., Reynolds, S., \& Creswell, C. (2008a). Future directions for child anxiety theory and treatment. Cognition and Emotion, 22, 385-394.

Field, A. P., \& Davey, G. C. L. (2001). Conditioning models of childhood anxiety. In W. K. Silverman \& P. A. Treffers (Eds.), Anxiety disorders in children and adolescents: research, assessment and intervention (pp. 187-211). Cambridge: Cambridge University Press.

Field, A. P., Hamilton, S. J., Knowles, K. A., \& Plews, E. L. (2003). Fear information and social phobic beliefs in children: A prospective paradigm and preliminary results. Behaviour Research and Therapy, 41, 113-123.

Field, A. P., \& Lawson, J. (2003). Fear information and the development of fears during childhood: Effects on implicit fear responses and behavioural avoidance. Behaviour Research and Therapy, 41, 1277-1293.

Field, A. P., \& Lawson, J. (2008). The verbal information pathway to fear and subsequent causal learning in children. Cognition and Emotion, 22, 459-479.

Field, A. P., Lawson, J., \& Banerjee, R. (2008b). The verbal threat information pathway to fear in children: The longitudinal effects of fear cognitions and the immediate effects on avoidance behavior. Journal of Abnormal Psychology, 117, 214-224.

Field, A. P., \& Lester, K. J. (in press). Learning of information processing biases in anxious children and adolescents. In J. Hadwin \& A. P. Field (Eds.), Information processing biases and anxiety: A developmental perspective. Chichester: Wiley.

Field, A. P., Lester, K. J., \& Cartwright-Hatton, S. (2008c). Cognitive-behavioural processes in the intergenerational transmission of fear to children. Paper presented at the annual congress of the association for the advancement of behaviour and cognitive therapy.

Field, A. P., \& Price-Evans, K. (2009). The behavioral inhibition system moderates the effect of the verbal threat information pathway on children's heart rate responses to novel animals. Behaviour Research and Therapy, 47, 431-436.

Field, A. P., \& Schorah, H. (2007). The verbal information pathway to fear and heart rate changes in children. Journal of Child Psychology and Psychiatry, 48, 1088-1093.

Field, A. P., \& Storksen-Coulson, H. (2007). The interaction of pathways to fear in childhood anxiety: A preliminary study. Behaviour Research and Therapy, 45, 3051-3059.

Fisak, B., \& Grills-Taquechel, A. E. (2007). Parental modeling, reinforcement, and information transfer: Risk factors in the development of child anxiety? Clinical Child and Family Psychology Review, 10, 213-231.

Gilbert, P. (1998). The evolved basis and adaptive functions of cognitive distortions. British Journal of Medical Psychology, 71, 447-463.

Graham, J., \& Gaffan, E. A. (1997). Fear of water in children and adults: Etiology and familial effects. Behaviour Research and Therapy, 35, 91-108.

Gray, J. A. (1981). A critique of Eysenck's theory of personality. In H. J. Eysenck (Ed.), A model for personality (pp. 246-276). Berlin: Springer.

Gray, J. A. (1987). Perspectives on anxiety and impulsivity: A commentary. Journal of Research in Personality, 21, 493-509.

Gray, J. A. (1988). The psychology of fear and stress (2nd ed.). Cambridge, UK: Cambridge University Press.

Gray, J. A., \& McNaughton, N. (2003). The neuropsychology of anxiety: An enquiry into the functions of the septo-hippocampal system (2nd ed.). New York: Oxford University Press.

Greenwald, A. G., McGhee, D. E., \& Schwartz, J. L. (1998). Measuring individual differences in implicit cognition: The Implicit Association Test. Journal of Personality and Social Psychology, 74, 1464-1480.

Gullone, E. (2000). The development of normal fear: A century of research. Clinical Psychology Review, 20, 429-451.

Hadwin, J. A., Garner, M., \& Perez-Olivas, G. (2006). The development of information processing biases in childhood anxiety: A review and exploration of its origins in parenting. Clinical Psychology Review, 26, 876-894.

Harrison, K., \& Cantor, J. (1999). Tales from the screen: Enduring fright reactions to scary media. Media Psychology, 1, 97-116.

Harvey, A., Watkins, E., Mansell, W., \& Shafran, R. (2004). Cognitive behavioural processes across psychological disorders. A transdiagnostic approach to research and treatment. Oxford: Oxford University Press.

Hawton, K., Salkovskis, P. M., Kirk, J., \& Clark, D. M. (1989). Cognitive therapy for psychiatric problems. Oxford: Oxford University Press.

Hoekstra, S. J., Harris, R. J., \& Helmick, A. L. (1999). Autobiographical memories about the experience of seeing frightening movies in childhood. Media Psychology, 1, 117-140.

Hofmann, S. G., Ehlers, A., \& Roth, W. T. (1995). Conditioning theory a model for the etiology of public speaking anxiety? Behaviour Research and Therapy, 33, 567-571.

Holmes, E. A., Creswell, C., \& O’Connor, T. G. (2007). Posttraumatic stress symptoms in London school children following September 11, 2001: An exploratory investigation of peritraumatic reactions and intrusive imagery. Journal of Behavior Therapy and Experimental Psychiatry, 38, 474-490.

Hoven, C. W., Duarte, C. S., Lucas, C. P., Wu, P., Mandell, D. J., Goodwin, R. D., et al. (2005). Psychopathology among New York City public school children 6 months after September 11 . Archives of General Psychiatry, 62, 545-552. 
Huijding, J., \& De Jong, P. J. (2007). Beyond fear and disgust: The role of (automatic) contamination-related associations in spider phobia. Journal of Behavior Therapy and Experimental Psychiatry, 38, 200-211.

James, A., Soler, A., \& Weatherall, R. (2005). Cognitive behavioural therapy for anxiety disorders in children and adolescents. The Cochrane Database of Systematic Reviews, (4). doi:10.1002/ 14651858.CD004690.pub2.

Kagan, J., Reznick, J. S., \& Snidman, N. (1987). The physiology and psychology of behavioral inhibition in children. Child Development, 58, 1459-1473.

Kelly, V. L., Barker, H., Field, A. P., Wilson, C., \& Reynolds, S. (2010). Can Rachman's indirect pathways be used to un-learn fear? A prospective paradigm to test whether children's fears can be reduced using positive information and modelling a non-anxious response. Behaviour Research and Therapy, 48, 164-170.

Kendall, P. C., Safford, S., Flannery-Schroeder, E., \& Webb, A. (2004). Child anxiety treatment: Outcomes in adolescence and impact on substance use and depression at 7.4-year follow-up. Journal of Consulting and Clinical Psychology, 72, 276-287.

Kessler, R. C., Berglund, P., Demler, O., Jin, R., Merikangas, K. R., \& Walters, E. E. (2005). Lifetime prevalence and age-of-onset distributions of DSM-IV disorders in the national comorbidity survey replication. Archives of General Psychiatry, 62, 593-602.

King, N. J., Clowes-Hollins, V., \& Ollendick, T. H. (1997). The etiology of childhood dog phobia. Behaviour Research and Therapy, 35, 77 .

King, N. J., Gullone, E., \& Ollendick, T. H. (1998). Etiology of childhood phobias: Current status of Rachman's three pathways theory. Behaviour Research and Therapy, 36, 297-309.

Lang, P. J. (1968). Fear reduction and fear behavior: Problems in treating a construct. In J. M. Schlien (Ed.), Research in psychotherapy (Vol. 3, pp. 90-103). Washington, DC: American Psychological Association.

Lang, P. J. (1985). The cognitive psychopathology of emotion: Fear and anxiety. In A. H. Tuma \& J. D. Maser (Eds.), Anxiety and the anxiety disorders (pp. 131-170). Hillsdale, NJ: Erlbaum.

Lawson, J., Banerjee, R., \& Field, A. P. (2007). The effects of verbal information on children's fear beliefs about social situations. Behaviour Research and Therapy, 45, 21-37.

Lengua, L. J., Long, A. C., Smith, K. I., \& Meltzoff, A. N. (2005). Pre-attack symptomatology and temperament as predictors of children's responses to the September 11 terrorist attacks. Journal of Child Psychology and Psychiatry, 46, 631-645.

Lester, K. J., Field, A. P., Oliver, S., \& Cartwright-Hatton, S. (2009). Do anxious parents interpretative biases towards threat extend into their child's environment? Behaviour Research and Therapy, 47, 170-174.

Lichtenstein, P., \& Annas, P. (2000). Heritability and prevalence of specific fears and phobias in childhood. Journal of Child Psychology and Psychiatry, 41, 927-937.

Lubow, R. E. (1973). Latent inhibition. Psychological Bulletin, 79, 398-407.

MacLeod, C., Mathews, A., \& Tata, P. (1986). Attentional bias in emotional disorders. Journal of Abnormal Psychology, 95, 15-20.

Matchett, G., \& Davey, G. C. L. (1991). A test of a disease-avoidance model of animal phobias. Behaviour Research and Therapy, 29, 91-94.

Matthews, G., Deary, I. J., \& Whiteman, M. C. (2003). Personality traits. New York: Cambridge University Press.

McLeod, B. D., Wood, J. J., \& Weisz, J. R. (2007). Examining the association between parenting and childhood anxiety: A metaanalysis. Clinical Psychology Review, 27, 155-172.

McNally, R. J., \& Steketee, G. S. (1985). The etiology and maintenance of severe animal phobias. Behaviour Research and Therapy, 23, 431-435.
Menzies, R. G., \& Clarke, J. C. (1993). The etiology of childhood water phobia. Behaviour Research and Therapy, 31, 499-501.

Menzies, R. G., \& Clarke, J. C. (1995). The etiology of phobias: A non-associative account. Clinical Psychology Review, 15, 23-48.

Merckelbach, H., Arntz, A., Arrindell, W. A., \& De Jong, P. J. (1992). Pathways to spider phobia. Behaviour Research and Therapy, 30, 543-546.

Merckelbach, H., De Jong, P. J., Muris, P., \& Van den Hout, M. A. (1996a). The etiology of specific phobias: A review. Clinical Psychology Review, 16, 337-361.

Merckelbach, H., \& Muris, P. (1997). The etiology of childhood spider phobia. Behaviour Research and Therapy, 35, 1031-1034.

Merckelbach, H., Muris, P., \& Schouten, E. (1996b). Pathways to fear in spider phobic children. Behaviour Research and Therapy, 34, 935-938.

Milgrom, P., Mancl, L., King, B., \& Weinstein, P. (1995). Origins of childhood dental fear. Behaviour Research and Therapy, 33, 313-319.

Mineka, S., \& Zinbarg, R. (2006). A contemporary learning theory perspective on the etiology of anxiety disorders-It's not what you thought it was. American Psychologist, 61, 10-26.

Muris, P. (2007). Normal and abnormal fear and anxiety in children and adolescents. Oxford: Elsevier.

Muris, P., Bodden, D., Merckelbach, H., Ollendick, T. H., \& King, N. J. (2003). Fear of the beast: A prospective study on the effects of verbal information on childhood fear. Behaviour Research and Therapy, 41, 195-208.

Muris, P., Du Plessis, M., \& Loxton, H. (2008a). Origins of common fears in South African children. Journal of Anxiety Disorders, $22,1510-1515$.

Muris, P., \& Field, A. P. (2008). Distorted cognition and pathological anxiety in children and adolescents. Cognition and Emotion, 22, 395-421.

Muris, P., \& Field, A. P. (in press). The normal development of fear in children and adolescents. In W. K. Silverman, \& A. P. Field (Eds.), Anxiety disorders in children and adolescents: Research, assessment and intervention, (2nd ed.). Cambridge: Cambridge University Press.

Muris, P., Huijding, J., Mayer, B., Leemreis, W., Passchier, S., \& Bouwmeester, S. (2009a). The effects of verbal disgust- and threat-related information about novel animals on disgust and fear beliefs and avoidance in children. Journal of Clinical Child and Adolescent Psychology, 38, 551-563.

Muris, P., Mayer, B., Huijding, J., \& Konings, T. (2008b). A dirty animal is a scary animal! Effects of disgust-related information on fear beliefs in children. Behaviour Research and Therapy, 46, 137-144.

Muris, P., \& Merckelbach, H. (2000). How serious are common childhood fears? II. The parents' point of view. Behaviour Research and Therapy, 38, 813-818.

Muris, P., Merckelbach, H., \& Collaris, R. (1997). Common childhood fears and their origins. Behaviour Research and Therapy, 35, 929-937.

Muris, P., Merckelbach, H., De Jong, P. J., \& Ollendick, T. H. (2002). The etiology of specific fears and phobias in children: A critique of the non-associative account. Behaviour Research and Therapy, 40, 185-195.

Muris, P., Merckelbach, H., Gadet, B., \& Moulaert, V. (2000a). Fears, worries, and scary dreams in 4- to 12-year-old children: Their content, developmental pattern, and origins. Journal of Clinical Child Psychology, 29, 43-52.

Muris, P., Merckelbach, H., Mayer, B., \& Prins, E. (2000b). How serious are common childhood fears? Behaviour Research and Therapy, 38, 217-228.

Muris, P., Merckelbach, H., Ollendick, T. H., King, N. J., \& Bogie, N. (2001). Children's nighttime fears: Parent-child ratings of 
frequency, content, origins, coping behaviors, and severity. Behaviour Research and Therapy, 39, 13-28.

Muris, P., Rassin, E., Mayer, B., Smeets, G., Huijding, J., Remmerswaal, D., et al. (2009b). Effects of verbal information on fear-related reasoning biases in children. Behaviour Research and Therapy, 47, 206-214.

Muris, P., Van der Heiden, S., \& Rassin, E. (2008c). Disgust sensitivity and psychopathological symptoms in non-clinical children. Journal of Behavior Therapy and Experimental Psychiatry, 39, 133-146.

Muris, P., Van Zwol, L., Huijding, J., \& Mayer, B. (in press). Mom told me that this animal is scary: Parents installing fear beliefs in their children via the negative information pathway. Behaviour Research and Therapy.

Öhman, A., Dimberg, U., \& Öst, L. G. (1985). Animal and social phobias: Biological constraints on learned fear responses. In S. Reiss \& R. R. Bootzin (Eds.), Theoretical issues in behavior therapy. Orlando, FL: Academic Press.

Öhman, A., \& Mineka, S. (2001). Fears, phobias, and preparedness: Toward an evolved module of fear and fear learning. Psychological Review, 108, 483-522.

Olatunji, B. O., \& Sawchuck, G. N. (2005). Disgust: Characteristic features, social manifestations, and clinical implications. Journal of Social and Clinical Psychology, 24, 932-962.

Ollendick, T. H. (1983). Reliability and validity of the Revised Fear Survey Schedule for Children (FSSC-R). Behaviour Research and Therapy, 21, 685-692.

Ollendick, T. H., \& King, N. J. (1991). Origins of childhood fears: An evaluation of Rachman's theory of fear acquisition. Behaviour Research and Therapy, 29, 117-123.

Ollendick, T. H., \& King, N. J. (1998). Empirically supported treatments for children with phobic and anxiety disorders: Current status. Journal of Clinical Child Psychology, 27, 156167.

Ollendick, T. H., King, N. J., \& Frary, R. B. (1989). Fears in children and adolescents: Reliability and generalizability across gender, age, and nationality. Behaviour Research and Therapy, 27, $19-26$.

Ollendick, T. H., Yang, B., Dong, Q., Xia, Y., \& Lin, L. (1995). Perceptions of fear in other children and adolescents: The role of gender and friendship status. Journal of Abnormal Child Psychology, 23, 439-452.

Orbach, I., Vinkler, E., \& Har-Even, D. (1993). The emotional impact of frightening stories on children. Journal of Child Psychology and Psychiatry, 34, 379-389.

Öst, L. G. (1987). Age of onset in different phobias. Journal of Abnormal Psychology, 96, 223-229.

Öst, L. G., \& Hugdahl, K. (1981). Acquisition of phobias and anxiety response patterns in clinical patients. Behaviour Research and Therapy, 19, 439-447.

Otto, M. W., Henin, A., Hirshfeld-Becker, D. R., Pollack, M. H., Biederman, J., \& Rosenbaum, J. F. (2007). Posttraumatic stress disorder symptoms following media exposure to tragic events: Impact of $9 / 11$ on children at risk for anxiety disorders. Journal of Anxiety Disorders, 21, 888-902.

Pearce, J. M., \& Hall, G. (1980). A model for Pavlovian learning: Variations in the effectiveness of conditioned but not unconditioned stimuli. Psychological Review, 87, 532-552.

Poulton, R., \& Menzies, R. G. (2002). Non-associative fear acquisition: A review of the evidence from retrospective and longitudinal research. Behaviour Research and Therapy, 40, 127-149.
Price-Evans, K., \& Field, A. P. (2008). A neglectful parenting style moderates the effect of the verbal threat information pathway on children's heart rate responses to novel animals. Behavioural and Cognitive Psychotherapy, 36, 473-482.

Rachman, S. J. (1977). The conditioning theory of fear acquisition: A critical examination. Behaviour Research and Therapy, 15, 372387.

Rachman, S. J. (1991). Neo-conditioning and the classic theory of fear acquisition. Clinical Psychology Review, 11, 155-173.

Ragan, K. (2006). Outfoxing fear: Folktales from around the world. New York: Norton.

Remmerswaal, D., \& Muris, P. (in press). "Will a Cuscus bite you, if he shows his teeth?" Inducing a fear-related confirmation bias in children by providing verbal threat information to their mothers. Journal of Anxiety Disorders.

Rose, R. J., \& Ditto, W. B. (1983). A developmental-genetic analysis of common fears from early adolescence to early adulthood. Child Development, 54, 361-368.

Rothbart, M. K., Ahadi, S. A., \& Evans, D. E. (2000). Temperament and personality: Origins and outcomes. Journal of Personality and Social Psychology, 78, 122-135.

Sale, R. (1978). Fairy tales and after. Cambridge, MA: Harvard University Press.

Smith, S. L., \& Moyer-Gusé, E. (2006). Children and the war on Iraq: Developmental differences in fear responses to television news coverage. Media Psychology, 8, 213-237.

Smith, S. L., \& Wilson, B. J. (2002). Children's comprehension of and fear reactions to television news. Media Psychology, 4, 1-26.

Stevenson, J., Batten, N., \& Cherner, M. (1992). Fears and fearfulness in children and adolescents: A genetic analysis of twin data. Journal of Child Psychology and Psychiatry, 33, 977-985.

Tellegen, A. (1985). Structure of mood and personality and their relevance to assessing anxiety, with an emphasis on self-report. In A. H. Tuma \& J. D. Maser (Eds.), Anxiety and the anxiety disorders (pp. 681-706). Hillsdale, NJ: Erlbaum.

Terr, L. C., Bloch, D. A., Michel, B. A., Shi, H., Reinhardt, J. A., \& Metayer, S. (1999). Children's symptoms in the wake of Challenger: A field study of distant-traumatic effects and an outline of related conditions. American Journal of Psychiatry, 156, 1536-1544.

Tomarken, A. J., Mineka, S., \& Cook, M. (1989). Fear-relevant selective associations and covariation bias. Journal of Abnormal Psychology, 98, 381-394.

Valkenburg, P. M., Cantor, J., \& Peeters, A. (2000). Fright reactions to television. Communication Research, 27, 82-99.

Van der Molen, J. H. W., \& Bushman, B. J. (2008). Children's direct fright and worry reactions to violence in fiction and news television programs. Journal of Pediatrics, 153, 420-424.

Vasey, M. W., \& MacLeod, C. (2001). Information-processing factors in childhood anxiety: A review and developmental perspective. In M. W. Vasey \& M. R. Dadds (Eds.), The developmental psychopathology of anxiety (pp. 253-277). New York: Oxford University Press.

Watson, J. B., \& Rayner, R. (1920). Conditioned emotional reactions. Journal of Experimental Psychology, 3, 1-14.

Westenberg, P. M., Drewes, M. J., Goedhart, A. W., Siebelink, B. M., \& Treffers, P. D. A. (2004). A developmental analysis of selfreported fears in late childhood through mid-adolescence: Social-evaluative fears on the rise? Journal of Child Psychology and Psychiatry, 45, 481-495.

Zipes, J. (1979). Breaking the magic spell: Radical theories of folk and fairy tales. New York: Routledge. 